
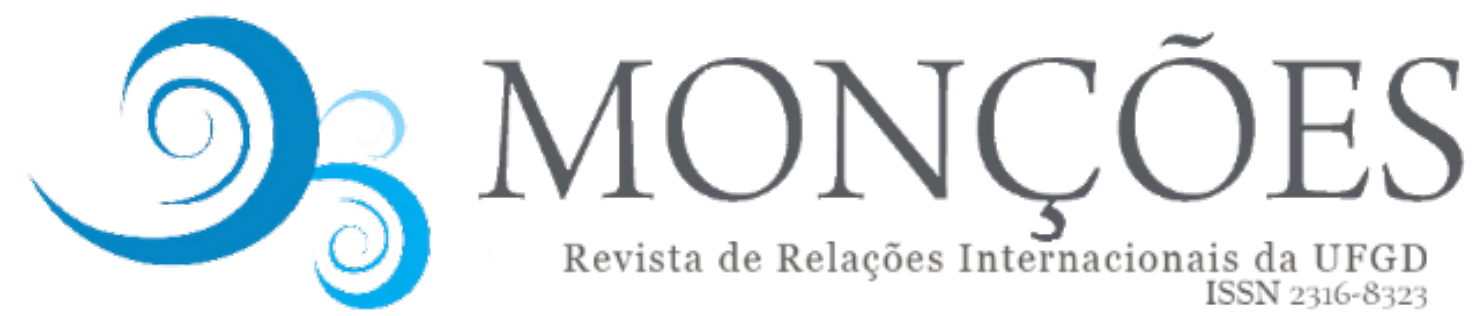

Revista de Relações Internacionais da UFGD

ISSN 2316-8323

\title{
ENTREVISTA COM JOÃO PONTES NOGUEIRA
}

\section{ENTREVISTADORAS:}

JOÃO NACKLE URT

Professor da Universidade Federal da Grande Dourados

LARA MARTIM RODRIGUES SELIS
Professora do Instituto de Economia e Relações Internacionais da Universidade de Uberlândia

VICTOR COUTINHO LAGE

Professor do Instituto de Humanidades, Artes e Ciências Professor Milton Santos (IHAC) da Universidade Federal da Bahia (UFBA)

João Pontes Nogueira possui graduação em Economia pela Universidade Federal do Rio de Janeiro (1984), mestrado em Relações Internacionais pela Pontifícia Universidade Católica do Rio de Janeiro (PUC-Rio, 1994) e doutorado em Relações Internacionais pela University of Denver (1998). Desenvolveu sua pesquisa de Pós-Doutorado na Universidade de Victoria (UVIC), Canadá, onde atou com professor visitante. É professor adjunto do Instituto de Relações Internacionais (IRI) da PUC-Rio desde 2000. Foi secretário executivo e diretor da Associação Brasileira de Relações Internacionais ( $A B R I$, 2005-2009), da qual foi um dos fundadores. Atua, principalmente, nos seguintes temas: teoria das relações internacionais, sociologia política internacional, desigualdade na política mundial, humanitarismo, e o lugar das cidades na política mundial. Foi diretor do IRI/PUC-Rio entre 2008 e 2012 e supervisor-geral do Centro de Estudos dos Países BRICS (BRICS Policy Center) durante o mesmo período. Foi editor-chefe, com Jef Huysmans, da revista International Political Sociology (IPS), da International Studies Association (ISA), de 2012 a 2016, e é membro do conselho editorial de diversas revistas nacionais e internacionais. 
Nota introdutória das entrevistadoras: A entrevista abaixo, realizada por e-mail, está dividida em duas partes. Na primeira, de escopo mais amplo, discute-se a relação do campo das Relações Internacionais com a universidade e o debate público. Já na segunda parte, focamos nossas perguntas na teorização do campo pensada a partir do Brasil.

\section{O campo das Relações Internacionais, a universidade e o debate público}

Pergunta: Quando se pensa no ambiente universitário nas últimas décadas, podemos identificar ao menos quatro transformações em curso: um processo de inserção no ambiente universitário de regras e métricas características do funcionamento do mercado (por exemplo, o produtivismo e a competitividade); um fortalecimento da concepção de que a universidade é um momento de preparação e de transição para o "mercado de trabalho"; um ímpeto anti-intelectual que busca deslegitimar o lugar social e epistêmico da universidade; e uma crescente presença de grupos historicamente marginalizados das instituições de ensino superior que têm pressionado por mudanças no ambiente universitário. Neste contexto, qual a sua visão sobre como devem se dar: (i) a tríade ensino-pesquisa-extensão; e (ii) a relação entre as universidades e os âmbitos "profissionais" ligados ao campo das Relações Internacionais (diplomacia, comércio exterior, organismos internacionais, etc.)?

Resposta: A relação entre universidade e sociedade é, sem dúvida, um bom lugar para pensar o campo das RIs no Brasil hoje. Em termos mais gerais, a universidade sempre expressa contradições entre as condições em que a atividade acadêmica está inserida e o tipo de conhecimento e aprendizado que produzimos. É comum pensar esta relação em termos de esferas separadas, como se a universidade fosse insulada do 'mundo real' para o qual ela prepara as gerações mais jovens. Também tendemos a pensá-la como um espaço autônomo a partir do qual podemos pensar com relativa liberdade, escapando do processo de mercantilização da cultura que caracteriza o capitalismo contemporâneo. 
As linhas que delimitam estes espaços são, na verdade, bastante opacas. Os diferentes saberes sobre, digamos, a saúde, os direitos, ou o internacional, circulam em múltiplos lugares e são articulados pelos diferentes atores. Creio que, para entendermos como a racionalidade de mercado adquiriu grande centralidade na definição de currículos e processos de ensino e pesquisa, precisaríamos olhar para as trajetórias dos saberes e aprendizados que foram cristalizados em certos ambientes institucionais. Por exemplo, no caso dos critérios de avaliação de programas e projetos de pesquisa, a universidade brasileira internalizou modelos orientados para a medição de resultados e impactos concebidos pela corrente managerialista (da escola de New Public Management) muito dominante no ambiente universitário britânico e promovido por grande número de agências de desenvolvimento (como o Banco Mundial e a OECD). Hoje adotamos rankings, fatores de impacto, relevância social, e muitos outros indicadores de produtividade típicos do novo maganagerialismo, como parâmetros para avaliar a qualidade do ensino e da pesquisa. Se olharmos para as recentes mudanças nos critérios da avaliação de programas de pós-graduação, podemos identificar essa tendência com clareza.

Em parte, este processo resulta das estratégias de internacionalização da universidade brasileira, que respondia à necessidade de criar redes de colaboração com pesquisadores de outros países depois de um longo período de isolamento da academia brasileira durante o regime militar. O mesmo processo, contudo, criou as condições para que as métricas de desempenho fossem gradualmente assimiladas, seja através de condicionantes técnicos inseridos em linhas e editais de financiamento, seja a partir da adoção de 'boas práticas' de avaliação introduzidas por acordos de cooperação e mecanismos de ranqueamento. Na medida em que estes dispositivos de controle e gerenciamento da educação foram sendo disseminados, a interface com o mercado alcançou um patamar mais intenso na medida em que universidade e empresas passaram a compartilhar uma linguagem sobre produtividade, desempenho e resultados. Estas tendências parecem ter estimulado, por exemplo, a criação de mestrados profissionais voltados para políticas públicas, comércio, defesa, o que, em princípio, poderia ser considerado um desenvolvimento positivo do campo. Temo, contudo, que expressem um movimento no sentido de definir as Relações Internacionais como um 
conhecimento profissionalizante e, em consequência, inibir a consolidação dos programas de pós-graduação acadêmicos, onde deveria se concentrar a produção intelectual da área.

Esta lógica de mercado parece estar pressionando os cursos de graduação a redefinir suas grades com base no imperativo da profissionalização, da produção de capital humano, principal mote da racionalidade neoliberal imposta à educação superior. Creio que deveríamos resistir a este processo e continuar a construir o campo das RI no Brasil como um lugar de reflexão e pensamento crítico sobre as transformações da política mundial e suas articulações com as mutações da formação social brasileira. Isto não quer dizer que não devamos nos preocupar com o futuro profissional dos estudantes de Relações Internacionais, mas sim que sua inserção no mercado de trabalho deve ser orientada por um saber capaz de pensar e entender os múltiplos fenômenos produzidos em espaços transnacionais. Em outras palavras, não deveríamos deixar o mercado definir o que é o internacional, isso seria relegar a área no Brasil a um lugar subordinado e irrelevante.

Finalmente, respondendo à última parte da pergunta, as Relações Internacionais foram, de fato, por muito tempo associadas a certas práticas estatais, em especial a diplomacia. Este vínculo claramente perdeu sua importância já que a disciplina já não é tão definida pelo seu estado-centrismo. Em outras palavras, a divisão entre uma esfera nacional e o espaço internacional por fronteiras territoriais do estado já não é capaz de definir o objeto de estudo da área. Eu entendo que muitos resistem a abrir mão da relativa clareza que essa divisão confere a nosso fazer acadêmico e à prática profissional. Recentemente, fiz uma palestra na qual defendia que a teoria de RI não poderia mais se contentar com reivindicar um saber específico sobre relações entre estados em um ambiente anárquico. A reação foi de perplexidade e mesmo de certa insatisfação. Meu argumento, por outro lado, é que, ao entender que o internacional atravessa uma multiplicidade de dimensões da vida social, nosso horizonte de investigação, bem como nossas competências para agir no mundo, se ampliam. Neste sentido, a diplomacia se torna um universo pequeno e muito menos relevante para os estudos internacionais e não deveria considerada como a opção natural de carreira do estudante de RI. Quanto 
ao comércio internacional, francamente, tenho dificuldade em imaginar o que essa atividade tem a ver com nossa disciplina.

Pergunta: Ainda considerando as transformações no ambiente universitário apontadas acima, como você enxerga o lugar do campo de RI na discussão acadêmica e no debate público no Brasil? Que contribuição singular, se alguma, o campo teria para o entendimento das transformações sociais e políticas no país hoje?

Resposta: Há, sem dúvida, enormes desafios à participação da universidade no debate público atual no Brasil, em particular talvez para as ciências sociais. Creio que exista a dificuldade adicional de entender quais são os contornos deste debate público que, no momento, não parecem estar muito claros. O campo das RI cresceu muito nos últimos anos, é muito diverso e confesso não ter uma imagem muito precisa de como ele se estrutura hoje. Talvez tenha melhores condições para falar do processo de consolidação da área no país e sua trajetória, mas deixo isto para a pergunta seguinte. Por outro lado, um pouco na linha da resposta anterior, eu diria que, na minha modesta opinião, as Relações Internacionais, enquanto campo de saber, são um lugar privilegiado para pensar os problemas do país hoje. Evitando uma resposta por demais extensa, destaco dois pontos. O primeiro diz respeito às possibilidades de pensar criticamente. Se, como defendi antes, o problema do internacional se apresenta principalmente nos limiares, nos limites, nas fronteiras que dividem e constituem espaços políticos, campos sociais, modos de representação, ordens soberanas, discriminações, a problematização das práticas que definem tais limites oferece possibilidades de criticar as relações de poder que estão em processo de reconfiguração hoje. Por exemplo, a forma como se está repensando a integração do ecossistema amazônico às cadeias produtivas globais do agronegócio e do extrativismo redefine, de forma potencialmente extrema, a relação entre território e direitos, antes baseada na possível sustentabilidade do desenvolvimento em sua articulação com os modos de vida dos povos indígenas da região. Trata-se de um processo que coloca em questão a forma como a cidadania funciona como dispositivo de governo de populações sujeitas a certas hierarquias de valorização da vida. 
O segundo ponto diz respeito às possibilidades que os estudos em relações internacionais oferecem para entendermos a complexidade das transformações em curso, como as novas práticas de produção de insegurança; os padrões mais radicais de exclusão social; a precarização do trabalho; a difusão de tecnologias de vigilância e controle; a multiplicação das formas de desigualdade e de estratificação social. Todos estes processos se caracterizam por conexões com circuitos transnacionais de produção de conhecimento; redes de especialistas; dispositivos de governança e monitoramento de políticas públicas; esquemas de classificação e ranqueamento; etc. que atravessam fronteiras entre público e privado e entre local e global. Esta configuração transversal dos saberes e problemas de pesquisa que hoje caracterizam a área é o que a torna tão singular em um universo onde a delimitação mais rigorosa dos espaços sociais e analíticos (entre nacional e internacional, por exemplo) dificulta nossa compreensão do mundo contemporâneo.

Pergunta: Toda narrativa sobre um campo de conhecimento é, em certa medida, política, apontando e promovendo possibilidades, ao mesmo tempo em que marginaliza temas considerados de menor importância. Partindo desse pressuposto, como você narraria a formação e consolidação do campo de Relações Internacionais no Brasil? Como tal trajetória resulta em potencialidades no campo hoje e quais importantes contribuições foram marginalizadas?

Resposta: A área de Relações Internacionais no Brasil se forma no contexto da transição democrática, ou seja, a partir dos anos 80 , quando os primeiros programas de graduação e pós-graduação se organizam. O regime militar via com desconfiança o estudo da política internacional nas universidades. Neste sentido, a formação do campo é fortemente marcada pelo clima de efervescência intelectual na sociedade brasileira em geral, e na acadêmica em particular, que se segue à Anistia e ao retorno de importantes intelectuais do exílio. É claro que certas burocracias do estado como o Itamaraty e a Escola Superior de Guerra se encarregavam de refletir e pensar estrategicamente a política externa e o posicionamento do país no sistema internacional da Guerra Fria. Contudo, o desafio de repensar o país em suas relações internacionais no período 
democrático produziu um distanciamento salutar da área em relação àquelas instituições, conferindo maior autonomia a seu processo de institucionalização bem como a sua agenda de pesquisa. Esta, na verdade, coincide em grande parte com o movimento de abertura, priorizando as questões da transição democrática, de um desenvolvimento menos dependente e do combate às desigualdades gritantes do capitalismo na América Latina. Em outras palavras, a evolução da área, principalmente nas décadas de 80 e 90 , acompanhou as transformações na sociedade brasileira, na região e no sistema internacional, refletindo em particular sobre os problemas relacionados à nova 'inserção internacional' do Brasil democrático na nova ordem mundial. O estudo das peculiaridades das transições democráticas na América Latina estimulou a reflexão sobre a integração regional e modelos de reforma do Estado, por exemplo. O debate sobre um novo modelo de desenvolvimento influenciou o estudo de instituições e regimes e a maneira como foi incorporada a questão da globalização na pauta de economia política internacional e na pesquisa sobre movimentos sociais globais.

Como sabemos, o impacto da internacionalização dos processos de mudança no país impulsionou o crescimento exponencial dos programas de graduação em Relações Internacionais que, ao final do milênio, chegavam a mais de cem. $O$ ritmo na pósgraduação foi mais lento, mas nem por isso menos significativo. A questão de fundo que se colocava, creio, era a de pensar a especificidade da contribuição da área para a pesquisa dos processos de transformação em curso. Em que medida as Relações Internacionais eram capazes de produzir conhecimento que fosse mais do que complementar (ou mesmo derivado) das demais ciências sociais? Esta questão se arrasta até, pelo menos, o momento da fundação da Associação Brasileira de Relações Internacionais (ABRI), em 2005, e se estende pelos anos seguintes quando, por exemplo, finalmente se reconhece a existência da área em comitês científicos da CAPES e do CNPq. Apesar do evidente dinamismo do campo, muitos ainda o viam como uma esfera interdisciplinar e um tanto periférica no universo acadêmico brasileiro.

Os obstáculos na esfera político-institucional introduziram contradições que ainda hoje afetam a área. Por um lado, o ethos crítico que marcou a emergência dos estudos internacionais na era da abertura inspirou uma geração de pesquisadores interessados em novas perspectivas na disciplina que permitissem entender a complexidade das 
transformações na política mundial. Para estes era preciso afastar-se do cânone tradicional das Relações Internacionais e explorar as contribuições da virada crítica, desde a desconstrução da imaginação soberana, da articulação espaço-temporal da comunidade política moderna, seu nacionalismo metodológico e a violência epistêmica do positivismo. Evidentemente, esta postura implicava na rejeição de uma concepção do internacional enquanto estado de natureza onde a política se reduz a competição e sobrevivência. Ou seja, uma rejeição à concepção clássica que fundamentava a especificidade do campo vis-à-vis as demais ciências sociais. Ora, para muitos, esta opção ia de encontro tanto ao imperativo de consolidação da área enquanto campo delimitado de saber, quanto às exigências de uma institucionalização bastante contestada. Mais ainda, para um conjunto importante de acadêmicos, a agenda fundamental era a da autonomia da política externa, da inserção soberana do Brasil na globalização e da centralidade do Estado na direção do novo modelo de desenvolvimento. Esta orientação combinava uma problemática já clássica nas ciências sociais - a da superação do caráter dependente e periférico da formação social brasileira - com perspectivas mais convencionais como o realismo e o institucionalismo, que privilegiavam o estado como ator central em um ambiente anárquico dominado pela lógica dos ganhos relativos.

Esta caracterização é um tanto simplificadora, mas ilustra de forma aproximada tendências que continuaram a conviver no processo de consolidação da área no passado recente. Elas se manifestam, por exemplo, na diversidade dos diferentes programas de pós-graduação e na capacidade de grupos de pesquisadores, principalmente os mais jovens, de inovarem a agenda de pesquisa e a produção teórica no sentido de ampliar a capacidade do campo em intervir em temas cruciais da política contemporânea mundial, como as novas formas de hierarquização no sistema internacional, o papel de dispositivos de governança global na reprodução de modos de dominação, a persistência de um ethos eurocêntrico, patriarcal e indiferente ao racismo como elemento constitutivo do estado moderno, para citar apenas algumas questões. O lado institucional da disciplina, contudo, vem privilegiando temas da agenda de pesquisa mais próximos à definição dominante do que são as relações internacionais, como a segurança, a multipolaridade do sistema, o lugar das potências emergentes, a reforma das instituições 
multilaterais, políticas de defesa e o futuro do regionalismo. Todos temas relevantes, é claro, para as políticas de estado, mas muito pouco abertos a processos e conflitos que cada vez mais combinam público e privado, local e global, ou simplesmente a transversalidade das relações transnacionais que não cabem no imaginário soberano. Neste sentido, a institucionalização tem apresentado uma certa defasagem em relação à linhagem crítica originária do campo, bem como em relação ao dinamismo de muitos programas e redes de pesquisadores. É sintomático, por exemplo, que até hoje a ABRI não tenha uma área temática de gênero e relações internacionais. Este seria um exemplo bem explícito de marginalização de uma vertente de estudos internacionais absolutamente central para todo o pensamento crítico na disciplina há décadas. Trata-se de uma situação realmente inaceitável. Mas se esta, digamos, normalização da esfera institucional da área aponta para o risco de um certo esvaziamento resultante da rigidez de sua concepção, por outro lado sua renovação é sempre uma perspectiva possível considerando o grande dinamismo do campo como um todo.

Pergunta: São recorrentes em vários campos do conhecimento os apontamentos referentes à pouca interação entre a produção de conhecimento no Brasil e o que se produz nos outros países da América Latina e nos países do continente africano. Esses apontamentos parecem ainda mais pertinentes para a teorização em Relações Internacionais. Na sua visão, que aspectos nos ajudam a compreender esse quadro? Quais os pontos de contato mais promissores para o aprofundamento dessa interação?

Resposta: Há numerosas razões para o insulamento da produção intelectual brasileira em relação à América Latina e à África. Seria difícil abordar, com justiça, as diferentes explicações para este fenômeno, não incomum em países continentais, mesmo os póscoloniais como a China e a Índia. Restringindo minha resposta apenas à teorização em $\mathrm{RI}$ eu destacaria dois aspectos. Primeiramente, como sabemos, a linhagem intelectual da disciplina é predominantemente anglo-saxã e sua formação enquanto 'ciência', essencialmente norte-americana. Não é preciso nos alongarmos neste ponto, já bastante 
repetido desde a publicação do famoso artigo de Stanley Hoffmann. ${ }^{1}$ Esta constatação, contudo, nos permite entender porque a introdução das Relações Internacionais como disciplina no Brasil, como aliás em tantos outros países, passou por um período de socialização do cânone dominante entre os pesquisadores locais. O controle e disseminação dos clássicos é uma condição indispensável para reivindicar um lugar na distribuição dos saberes convencionais organizados no sistema de ensino superior. Quando começamos a discutir o currículo mínimo de RI para as graduações que se multiplicavam no Brasil, procuramos forçar a introdução de matérias de teoria de RI que dessem conta da literatura de referência produzida na Inglaterra e nos Estados Unidos. Sem isso, não seria possível institucionalizar a área.

Por outro lado, como notei acima, este esforço de socialização do arquivo teórico das Relações Internacionais estava atravessado por tensões. Para muitos de nossa geração, a teoria de RI não só expressava uma geopolítica da produção do saber hierarquizada, mas principalmente gerava uma representação da política mundial que reproduzia formas de dominação existentes. Para um país periférico como o Brasil, o cânone simplesmente não servia. Mais ainda, ao nos voltarmos para a produção brasileira em RI - por exemplo, no trabalho de Helio Jaguaribe ${ }^{2}$ ou de Araújo Castro ${ }^{3}$ percebíamos que a incorporação do aparato conceitual das teorias convencionais limitava nossa capacidade de crítica da estrutura desigual do sistema internacional. Ou, no caso do pensamento latino-americano, o exemplo do realismo periférico de Carlos Escudé $^{4}$ oferecia uma escolha entre o alinhamento e uma busca de autonomia a custos inaceitáveis. Era, portanto, preciso engajar-nos em uma 'dupla crítica', quer seja dos paradigmas dominantes da disciplina anglo-saxã e, também, das formulações periféricas que os traduziam e adaptavam para pensar as relações internacionais do terceiro mundo

\footnotetext{
1 Trata-se do artigo: HOFFMANN, Stanley. "An American Social Science: International Relations". Daedalus, vol.106, n.3, p.41-60, 1977 (Nota das Entrevistadoras).

2 Helio Jaguaribe (1923-2018), pensador de vasta obra escrita e de intensa participação no debate público no país, dedicou grande parte dela à reflexão sobre nacionalismo, desenvolvimento e relações internacionais (Nota das Entrevistadoras).

3 João Augusto de Araújo Castro (1919-1975) foi diplomata, ocupando, entre outros, o cargo de ministro das Relações Exteriores entre 1963 e 1964, durante o governo de João Goulart (Nota das Entrevistadoras). ${ }^{4}$ Carlos Escudé (1948-) é um pensador argentino conhecido por sua teoria do "realismo periférico", a qual se tornou influente na formulação da política externa do governo de Carlos Menem, presidente da Argentina entre 1989 e 1999 (Nota das Entrevistadoras).
} 
nos termos da política de poder ou da mitigação de assimetrias via reformas do sistema multilateral e, eventualmente, da integração regional.

Neste contexto, o engajamento com o movimento crítico na disciplina, então em seu ápice, oferecia justamente elementos para uma crítica ao poder do mainstream norteamericano bem como aos fundamentos epistemológicos que o reproduziam. Daí a influência da teoria crítica de matriz marxiana, bem como do pós-estruturalismo, em um conjunto jovens pesquisadores brasileiros interessados em pensar a teoria de Rl a partir da periferia. O desafio, é claro, era como articular um pensamento crítico situado que não reproduzisse, simplesmente, os termos do quarto debate..$^{5} \mathrm{O}$ enfrentamento das limitações das teorias críticas para a condição periférica acabaria por nos empurrar na direção dos pensamentos pós-colonial e decolonial. Este foi o movimento mais promissor para abrir nossa reflexão sobre o internacional para os saberes produzidos na periferia, seja na América Latina, na Ásia e na África. Não se trata de um movimento simples, pois sua articulação em termos de uma teoria de RI esbarra na forma como as relações internacionais são concebidas em primeiro lugar. Mas este é um outro debate.

O segundo comentário que gostaria de fazer em resposta à pergunta quer apenas relativizar um pouco o insulamento intelectual brasileiro a que me referi no início, fazendo referência ao que disse antes sobre as linhagens intelectuais da área no Brasil, enraizadas na virada dos anos 80 . Ora, naquele momento há uma enorme efervescência intelectual no Brasil que, por um lado, se abria a vertentes intelectuais que vinham de fora e tinham sido censuradas e, por outro, recuperava o pensamento social brasileiro, a escola cepalina, a teoria da dependência para repensar a questão nacional e sua articulação com as mudanças internacionais. A teorização sobre a questão democrática na América Latina após o período autoritário é extremamente original. É pena que não

\footnotetext{
${ }^{5}$ Por "quarto debate", entenda-se o quarto debate teórico que, por certa perspectiva, marca a evolução das Relações Internacionais enquanto "disciplina". Nessa perspectiva, o "primeiro debate" teria ocorrido entre "realistas" e "idealistas" no entreguerras; o "segundo debate", entre "tradicionalistas" e "behavioristas" (ou "cientificistas") principalmente nos anos 60; o terceiro debate", nos anos 1970, seria "interparadigmático", marcado por correntes teóricas como "liberalismo", "realismo" e "marxismo"; já o "quarto debate" contraporia "positivistas" a "pós-positivistas", incluindo entre os últimos uma ampla variedade de correntes teóricas, conhecidas amiúde pelos rótulos de "pós-estruturalismo", "teoria crítica", "construtivismo", "feminismo", entre outras. A historiografia das Relações Internacionais centrada nesses chamados "grandes debates" vem sendo problematizada nas últimas décadas, algo retomado na resposta à próxima questão (Nota das Entrevistadoras).
} 
tenha sido mais apreciada nas relações internacionais que, infelizmente, ainda insistem em importar as tolices da teoria da paz democrática na pesquisa sobre segurança humana. Da mesma forma, o trabalho seminal de Carlos Nelson Coutinho, como por exemplo seu histórico ensaio sobre a 'Democracia como valor universal', foi pouco assimilado nos estudos gramscianos de relações internacionais no Brasil. ${ }^{6}$ Talvez devamos recuperar aquele momento de interação intensa, pelo menos entre intelectuais latino-americanos, para identificar os circuitos através dos quais as convergências produziram contribuições originais. O crescimento da Clacso é um exemplo muito significativo do quanto o pensamento latinomericano é hoje parte integral do debate teórico nas ciências sociais. Da mesma forma, a rede de estudos decoloniais (conhecida como grupo de pesquisas modernidade/colonialidade) se consolidou como um polo de pensamento original e singular sobre a experiência da modernidade na história do continente. Estas redes têm tido impacto crescente na pesquisa em relações internacionais que podem ser verificados em trabalhos apresentados em conferências e em dissertações e teses defendidas. O fato, contudo, é que não existem redes de colaboração em pesquisa e intercambio intelectual semelhantes em nosso campo. Tratase de um desafio que precisamos enfrentar.

\section{Teorização em Relações Internacionais a partir do Brasil}

Pergunta: Um aspecto comum entre muitos países é o da pouca valorização de reflexões teóricas, especialmente quando estas não se apresentam com alguma preocupação empírica explícita. Ao longo da sua trajetória, fica notório seu envolvimento no fortalecimento da discussão teórica no Brasil, tanto como pesquisador e professor quanto como diretor de instituto e editor de periódico. Tendo em vista esta experiência e

\footnotetext{
${ }^{6}$ Carlos Nelson Coutinho (1943-2012) foi responsável pela edição brasileira dos Cadernos do Cárcere, de Antonio Gramsci (publicada pela editora Civilização Brasileira), tendo sido também um de seus mais importantes intérpretes. O livro A Democracia como Valor Universal: notas sobre a questão democrática no Brasil (publicado pela primeira vez em 1979 na revista Encontros com a Civilização Brasileira e, no ano seguinte, pela Editora Ciências Humanas) teve grande impacto nos debates sobre a relação entre democracia e socialismo (Nota das Entrevistadoras).
} 
contribuição, como você vem pensando o ensino de teorização e a produção teórica em RI no Brasil?

Resposta: Quando voltei ao Brasil depois de concluir o doutorado defendendo uma tese teórica, logo percebi que para avançar na carreira teria que investir em um tema de pesquisa com corte mais empírico. Muitos colegas mais experientes me avisaram que não conseguiria financiamentos com projetos de cunho teórico. Creio que, naquela época, o final dos anos 90, havia uma percepção sobre o que eram as relações internacionais que enfatizava problemas relacionados a política externa, reforma do Estado, estratégias de desenvolvimento, institucionalização de regimes, entre outras questões bastante prementes da conjuntura política nacional e internacional. Esta era uma posição defendida, por exemplo, entre os colegas que vinham da ciência política. Isto não quer dizer que o debate teórico fosse secundário, ao contrário, mas ele ocorria principalmente na teoria social, na teoria política e na economia política, não tanto nas relações internacionais propriamente ditas. Muitos acreditavam que fazer teoria em RI era um luxo a que não podíamos nos permitir, que era coisa de país desenvolvido. Nossa tarefa era pensar os problemas da democratização e do desenvolvimento brasileiros. Este, aliás, continua a ser o traço marcante da disciplina no país hoje, apesar de tanta gente dizer que somos definidos por saberes importados, eurocêntricos, etc.

Ora, estas narrativas desconhecem ou ignoram a força com que a cultura acadêmica e o pensamento brasileiros determinaram e continuam determinando nossas agendas de pesquisa e autorizando o que podemos ou não fazer em termos de teoria. $O$ esforço do qual participei nos anos seguintes foi, portanto, o de internacionalizar as RI no Brasil através, inicialmente, do debate teórico, internalizando a contribuição da teoria crítica, do construtivismo e do pós-estruturalismo no enfrentamento do estatismo, do nacionalismo metodológico e do logocentrismo dos paradigmas dominantes. Acreditávamos que este movimento era fundamental para a 'dupla crítica' a que me referi acima, ou seja, ao atrelamento das RI no país a epistemologias estatistas e modernizantes que inibiam o potencial crítico dos estudos internacionais. Foi neste contexto que procuramos trazer para o Brasil figuras de ponta como R.B.J. Walker, Mike Shapiro, Nicholas Onuf, Jens Bartelson, Naeem Inayatullah, Didier Bigo, Siba Grovougui, 
entre outros, ${ }^{7}$ como estratégia para interferir nos rumos do debate brasileiro, colocando a questão teórica como central para pensar o internacional a partir do Brasil. Na época a formulação era a de como fazer 'teoria na periferia', sendo o uso do termo periferia um significante um tanto quanto vazio e por isso mesmo capaz de fraturar os conceitos soberanistas em torno dos quais giravam as discussões sobre autonomia, inserção internacional, democratização das estruturas de governança global, multipolaridade etc. Creio que esse movimento teve algum impacto nos rumos da área ainda que com claros altos e baixos. Minha impressão é que a geração de pesquisadores mais jovens tem assumido a liderança na proposição de novas agendas teóricas críticas, como evidencia a organização deste número especial de Monções.

Do ponto de vista institucional o projeto mais importante com o qual colaborei foi a construção do Instituto de Relações Internacionais da Pontifícia Universidade Católica do Rio de Janeiro (IRI/PUC-Rio) como um centro de pensamento crítico em RI no Brasil. Mais recentemente, a edição da revista International Polítical Sociology (IPS), em parceria com meu colega Jef Huysmans ${ }^{8}$, sem dúvida marcou e continua orientando minha atividade acadêmica nos últimos anos. A IPS retoma a linhagem intelectual da virada crítica dos anos 80 e 90 e propõe uma agenda de pesquisa informada pela sociologia crítica e pelo pós-estruturalismo que olha para processos e práticas situados nos limites do internacional moderno. Como uma abordagem que explora os limiares, as fronteiras e as práticas que delimitam espaços políticos, a sociologia política internacional desloca os lugares epistêmicos a partir dos quais pensamos a política mundial, desestabilizando as topologias que constituem a separação entre nacional e internacional, local e global, universal e particular. Uma das consequências desta perspectiva é olhar para os interstícios, para as práticas quotidianas, para o situacional, tentando evitar leituras da fragmentação e descentralização do poder a partir de macro narrativas sobre o caráter global, eurocêntrico ou patriarcal do sistema internacional. Ao

\footnotetext{
7 Tais pensadores se destacaram nas últimas décadas por articularem diferentes perspectivas teóricas em interação com o campo de Relações Internacionais. Com diferentes frequências e intensidades, todos eles já ministraram ou ainda ministram cursos no Brasil, principalmente no Instituto de Relações Internacionais da Pontifícia Universidade Católica do Rio de Janeiro (IRI/PUC-Rio) (Nota das Entrevistadoras).

8 Jef Huysmans é professor da School of Politics and International Relations da Queen Mary, University of London (Nota das Entrevistadoras).
} 
deslocar as narrativas totalizantes sobre o internacional e ao problematizar as práticas soberanas que o delimitam e o constituem, abre-se um leque de problemas antes estranhos à disciplina. Estudos de cidadania, policiamento, violência urbana eram todos circunscritos à esfera do doméstico e não considerados próprios de pesquisas de RI. A sociologia política internacional questiona essas divisões e trabalha na transversalidade das formas de poder e processos de subjetivação que reestruturam o político e o social hoje.

Meus interesses teóricos estão muito ligados a este olhar sobre o internacional, orientados pela tentativa, justamente, de trazer a teoria para o centro do debate, em particular na recuperação e reformulação de suas linhas críticas. Entre os problemas que levantamos está o debate sobre a relação entre macro e micro, de teoria e prática, do potencial crítico das práticas contemporâneas de resistência, a obsolescência da questão da ordem mundial, a relevância do conceito de estrutura, para mencionar alguns dos conceitos que considero importantes para revitalizar a teoria crítica de RI. No que diz respeito ao ensino de teoria eu mencionaria, principalmente, o afastamento do modelo tradicional estruturado em torno das correntes teóricas, dos grandes debates e das 'viradas'. Se durante muito tempo estes foram dispositivos didáticos úteis para a socialização de alunos na disciplina, hoje já não refletem a diversidade da produção teórica e a riqueza da agenda de pesquisa dos estudos internacionais. Principalmente precisamos superar o já esgotado esquema de debates entre realismo e liberalismo, que nada explica e em nada ajuda a entender a política mundial contemporânea.

Pergunta: Convencionou-se chamar de "divisão global do trabalho intelectual" a condição na qual pesquisadoras(es) do Norte produzem Teoria de teor universal e com alcance global, enquanto pesquisadoras(es) periféricas(os) produzem material empírico e interpretações locais a partir de perspectivas particulares. Como pesquisadoras(es) em condições consideradas periféricas poderiam e deveriam se posicionar diante disso?

Resposta: A produção teórica tem primazia na estruturação do campo das Relações Internacionais; trata-se de um capital simbólico determinante, em contraste com outras disciplinas onde, por exemplo, a experimentação situa os acadêmicos no centro do 
campo. Por isso, nos Estados Unidos a disciplina gira em torno de programas de pesquisa constituídos por grupos de pesquisadores alinhados com determinado paradigma. A divisão internacional do trabalho teórico da disciplina reflete em grande parte esta concentração de poder na academia norte-americana e o papel que ela desempenhou na institucionalização das RI no pós-guerra. Os pesquisadores em países periféricos ocupam um lugar marginal na geografia da produção do saber em RI tanto em razão de como se estrutura o campo mundialmente como em função de seu lugar subordinado na hierarquia civilizacional do internacional moderno. Os estudos de área são, como sabemos, uma invenção norte-americana que produz este tipo de violência epistêmica onde, por exemplo, a América Latina é o objeto de um saber superior situado nos centros hegemônicos e o pesquisador latino-americano é o informante da fenomenologia sempre estranha desses lugares distantes e atrasados. Não há dúvida que este imaginário persiste nas representações dos acadêmicos da área em países centrais, até mesmo entre aqueles considerados críticos ou progressistas. Em outras palavras, se você quer fazer teoria, é difícil ser levado a sério nos centros acadêmicos do Norte e nas revistas científicas de ponta.

O problema se acentua, porém, quando esta racionalidade se reproduz localmente, como comentei acima. Ou seja, a própria academia do 'Sul' muitas vezes aceita a divisão do trabalho e relega o trabalho teórico a um lugar secundário. Esta atitude era muito presente há vinte anos, mas creio que ainda perdura, por exemplo, na área aqui no Brasil, onde a produção teórica continua muito reduzida e pouco valorizada. Ou, alternativamente, o trabalho conceitual é orientado por problemas surgidos nos estudos de política externa ou de segurança, conferindo-Ihes mais relevância e aproximando-os de agendas de pesquisa associadas aos desafios das Relações Internacionais do Brasil e aos debates dentro da comunidade acadêmica do país. Em outras palavras, a forma com que pesquisadores locais muitas vezes lidam com as barreiras à entrada nas esferas acadêmicas internacionais é abster-se de publicar, ou mesmo submeter, artigos em periódicos estrangeiros.

Finalmente, se, de fato, os obstáculos estruturais à produção de teoria na periferia ainda perduram, é importante dizer que o contexto vem mudando gradualmente. Por exemplo, há uma presença importante e um peso mais significativo de pesquisadores do 
Sul nas diferentes seções da International Studies Association (ISA) que se refletem em mudanças claras nos programas das conferências anuais, na organização mais frequente de conferências em países do Sul e na adoção de políticas de abertura e inclusão nos periódicos científicos da Associação. Podemos encontrar tendências semelhantes em revistas de ponta na Europa também, como a Review of International Studies e a Millennium, entre outras. Estes espaços refletem o impacto da expansão da área globalmente e também a influência, por exemplo, das teorias pós-coloniais nas Relações Internacionais, cujo trabalho de 'provincialização' do mundo anglo-saxão foi sendo progressivamente assimilado entre os grupos de pesquisadores mais críticos do campo. Neste sentido, creio que o trabalho a ser feito por pesquisadores em países como o Brasil é explorar tais aberturas, resistir ao insulamento em suas próprias comunidades nacionais e engajar-se no cada vez mais diverso debate teórico ocorrendo em redes muito mais dispersas, diversificadas e descentralizadas que caracterizam a área hoje no mundo. Não quero soar excessivamente otimista, minha intenção é mais propriamente a de contestar a resignação que muitas vezes atinge colegas e estudantes quando consideram seu engajamento em publicações e conferências internacionais. Acredito que a área tenha mudado muito nos últimos vinte anos, tem-se fragmentado em muitos centros distintos, longe da hegemonia norte-americana. É possível que as condições sejam, portanto, favoráveis à formação de redes transnacionais de pesquisa muito mais inclusivas. É claro que este potencial exige que levemos a sério o investimento no trabalho teórico aqui no Brasil como elemento estratégico da transformação das RI em um lugar de criação de pensamento crítico e alternativo à imagem dogmática do internacional que ainda prevalece na disciplina.

Pergunta: Uma parte cada vez mais relevante de teorizações no campo de RI, em particular a partir dos anos 2000 , chama a atenção para a necessidade de pensarmos não apenas o conceito de classe, mas também de conduzirmos estudos teóricos sobre raça, etnia, sexualidade e gênero. Como essas agendas impactam ou deveriam impactar configuração dos estudos das RI no Brasil? 
Resposta: Uma das tendências mais encorajantes do campo hoje no Brasil tem sido o impulso vigoroso no sentido da incorporação estudos teóricos de gênero e raça na produção acadêmica de RI. Como tantas coisas em nossa área, trata-se de uma correção tardia, especialmente no que diz respeito às teorias feministas, cujo papel foi fundamental no momento crítico dos anos 80 e 90 . Desde então já tínhamos contato com textos importantes, como a crítica de J. Ann Tickner ${ }^{9}$ aos princípios do realismo de Morgenthau, onde a racionalidade que desvenda o interesse nacional ao estadista (um homem naturalmente) é fundamentalmente masculina. Uma das críticas mais rigorosas ao positivismo também foi articulada por Tickner em sua análise dos pressupostos masculinizados dos modelos de ciência ocidentais, tão importantes para a construção dos paradigmas dominantes da disciplina. É, neste sentido, curioso e problemático que, depois de um investimento considerável na difusão do pensamento crítico em RI, somente agora os estudos de gênero tenham ganhado corpo no país. Não vejo como avançar na renovação da área de RI sem a participação do pensamento e movimento feministas, cuja organização e visibilidade cresceram enormemente nos últimos anos. A agenda de RI no Brasil ainda é dominada pela centralidade do estado como ator, objeto principal de políticas de segurança e defesa e horizonte normativo para uma suposta contra-hegemonia liderada por potencias emergentes. Daí a sedução das pautas do humanitarismo militarizado, no desenvolvimentismo gigantista e soberanista, hoje capturadas pelo autoritarismo misógino. O feminismo permite uma crítica a estas concepções estreitas e uma abertura para as questões da desigualdade e das hierarquias naturalizadas pelo imaginário internacional moderno.

Os estudos de raça e racismo tem uma trajetória um pouco diferente. Sua ausência nas RI do Brasil quase coincide com os silêncios na disciplina internacionalmente. A coletânea organizada por Robbie Shilliam sobre o tema foi publicada apenas em 2015; o livro de John Hobson sobre racismo científico e eurocentrismo nas Relações Internacionais sai em $2012 .{ }^{10}$ É claro que muito antes disso as teorias pós-coloniais e

9 J. Ann Tickner é professora da American University e é uma das principais teóricas feminista no campo de Relações Internacionais (Nota das Entrevistadoras).

${ }^{10}$ Trata-se, respectivamente, dos seguintes livros: ANIEVAS, Alexander; MANCHANDA, Nivi; e SHILLIAM, Robbie (eds.). Race and Racism in International Relations: Confronting the Colour Global Line (Londres e Nova York: Routledge, 2015); e HOBSON, John M. The Eurocentric Conception of World Politics: 
decoloniais já colocavam a raça como elemento central da razão e do poder coloniais creio que é dispensável citar a larga bibliografia a respeito. Mas, apesar da já consolidada influência destas teorias na produção acadêmica de relações internacionais, somente agora encontramos uma problematização do racismo como modo de dominação constitutivo do internacional moderno. No Brasil, já encontramos jovens pesquisadores explorando o pensamento afro-diaspórico brasileiro, o legado do quilombismo como imaginários excluídos da reflexão sobre a formação social do país e sua inserção no sistema internacional enquanto estado pós-colonial escravista. Há um enorme potencial crítico no desenvolvimento deste tipo de teorização que, espero, interferirá decisivamente nos rumos da área no Brasil.

Pergunta: Para encerrar, que indicações você daria para um estudante de Relações Internacionais que, hoje, gostaria de iniciar uma trajetória de formação em teorização? Por onde começar? Onde buscar e produzir recursos intelectuais, materiais e institucionais? Que desafios esperar e como se preparar para eles?

Resposta: Em primeiro lugar, eu diria que este é um momento propício para interessarse em teoria internacional, tanto pelas condições paradoxalmente favoráveis existentes na área hoje, quanto em função da fluidez dos eventos que atravessamos hoje no Brasil. Como mencionei, existe uma energia criativa entre os jovens pesquisadores de RI que promete coisas interessantes no campo teórico. Quanto ao contexto mais geral do país e do mundo, eu lembraria o que dizia Gilles Deleuze, que é nos momentos de decepção e cansaço que o pensamento luta para transformar-se, para ser outro, para deixar o dogmatismo e recomeçar algo novo. Este é o momento da crítica. Não fazemos teoria para entender o mundo, fazemos teoria, ou melhor, criamos conceitos para conseguirmos pensar. Em segundo lugar, eu diria que pensar teoricamente não exige muitos recursos, apenas a disposição de engajar, de forma aberta e até mesmo vulnerável, com autores que desafiam nossos dogmas, nossas opiniões, nossas representações familiares do

Western International Theory, 1760-2010 (Nova York: Cambridge University Press, 2012) (Nota das Entrevistadoras). 
mundo. Isto significa ler, é claro, os clássicos da teoria política e social, mas principalmente ler amplamente, sem descartar aqueles com quem não concordamos e sem nos rendermos ao presentismo e às modas que tanto contaminam nossos debates acelerados pelas mídias virtuais e pela competitividade da mercantilização acadêmica. Finalmente, eu diria que um desafio importante é pensar coletivamente, criar redes de trabalho e pesquisa conjuntas, ultrapassar fronteiras disciplinares, territoriais, epistemológicas. As relações internacionais falam sobre conexões e sobre a diferença. O desafio da teoria hoje é afirmar este ethos democrático. 